\title{
Inclusão no Ensino Superior: Percepção de estudantes com deficiência visual
}

\author{
Inclusion in Higher Education: Perception of students with visual impairment \\ Inclusión en Educación Superior: Percepción de estudiantes con discapacidades visuales
}

\author{
Rosamaria Reo Pereira \\ ORCID: https://orcid.org/0000-0002-6134-2245 \\ Universidade Federal do Pará, Brasil \\ E-mail: rosareoufpa@gmail.com \\ Rosana Assef Faciola \\ ORCID: https://orcid.org/0000-0002-0987-4527 \\ Universidade Federal do Pará, Brasil \\ E-mail: rosanassef@gmail.com \\ Fernando Augusto Ramos Pontes \\ ORCID: https://orcid.org/0000-0001-9569-943X \\ Universidade Federal do Pará, Brasil \\ E-mail: farp1304@hotmail.com \\ Viviam Rafaela Barbosa Pinheiro Freira \\ ORCID: https://orcid.org/0000-0003-3254-3897 \\ Universidade Federal do Pará, Brasil \\ E-mail: viviamrafaela@gmail.com \\ Simone Souza da Costa Silva \\ ORCID: https://orcid.org/0000-0003-0795-2998 \\ Universidade Federal do Pará, Brasil \\ E:mail: symon.ufpa@gmail.com
}

\begin{abstract}
Resumo
A pesquisa analisou as percepções dos estudantes com deficiência visual no que tange as dificuldades encontradas quanto à acessibilidade arquitetônica, tecnológica, metodológica e comunicacional da Universidade Federal do Pará (UFPA). A fim de atingir os objetivos delineados neste estudo, adotou-se a pesquisa caracterizada como exploratório e descritiva quanto ao objetivo, o estudo de caso quanto ao procedimento e a pesquisa quantitativa e qualitativa quanto á abordagem do problema. $\mathrm{O}$ estudo foi operacionalizado por meio da pesquisa de campo e de dados secundários a partir de documentos referentes as leis, decretos e portarias que regem a Educação Especial no sistema educacional brasileiro. Vinte participantes responderam ao questionário sociodemográfico e acadêmico e foram analisados por meio da estatística descritiva. Os participantes fizeram uma avaliação negativa em relação as barreiras de acessibilidade existentes na universidade. Alguns desses obstáculos precisam ser reavaliados pela instituição, que por sua vez, necessita se estruturar para atender as necessidades educacionais específicas desse alunado e oferecer os recursos necessários para favorecer o acesso e permanência desse público na instituição. Acredita-se que o conhecimento apropriado pode patrocinar o planejamento de ações afirmativas que favoreça a inclusão desses alunos.
\end{abstract}

Palavras-chave: Aluno com deficiência visual; Ensino superior; Acessibilidade.

\begin{abstract}
This research analyzed the perceptions of students with visual impairments who faced difficulties related to the architectural, technological, methodological and communicational accessibility at the Federal University of Pará. In order to achieve the objectives outlined in this study, the research was characterized as an exploratory and descriptive as to the objective, the case study as to the procedure and quantitative and qualitative research as to the approach of the problem. The study was done through field research and secondary data from documents referring to the laws, decrees and ordinances which is ruled through Special Education in the Brazilian educational system. Twenty participants answered the sociodemographic and academic questionnaire and were analyzed using descriptive statistics. The participants made a negative assessment regarding the accessibility barriers existing at the university. Some of these obstacles need to be reevaluated by the institution, which in turn, has to structure itself to face the specific educational needs of these students and offer the necessary resources to favor the access and permanence of this public in the institution. Appropriate knowledge can support the planning of affirmative actions that can favor the inclusion of these students.
\end{abstract}

Keywords: Student with visual impairment; Higher education; Accessibility. 


\begin{abstract}
Resumen
La investigación analizó las percepciones de los estudiantes con discapacidad visual con respecto a las dificultades encontradas en términos de accesibilidad arquitectónica, tecnológica, metodológica y comunicativa en la Universidad Federal de Pará (UFPA). Para lograr los objetivos planteados en este estudio, se adoptó una investigación caracterizada como exploratoria y descriptiva en cuanto al objetivo, el estudio de caso en cuanto al procedimiento y la investigación cuantitativa y cualitativa en cuanto al abordaje del problema. El estudio se hizo operativo a través de investigaciones de campo y datos secundarios de documentos referentes a las leyes, decretos y ordenanzas que rigen la Educación Especial en el sistema educativo brasileño. Veinte participantes respondieron el cuestionario sociodemográfico y académico y fueron analizados mediante estadística descriptiva. Los participantes hicieron una evaluación negativa con respecto a las barreras de accesibilidad existentes. Algunos de estos obstáculos deben ser reevaluados, que, a su vez, necesita estructurarse para satisfacer las necesidades educativas específicas de este estudiante y ofrecer los recursos necesarios para favorecer el acceso y la permanencia de este público. Se cree que el conocimiento apropiado puede apoyar la planificación de acciones afirmativas que favorezcan la inclusión de estos estudiantes.
\end{abstract}

Palabras clave: Estudiante con discapacidad visual; Enseñanza superior; Accesibilidad.

\title{
1. Introduçãa
}

A chegada de estudantes com deficiência nas escolas de ensino regular no Brasil se constitui um direito cuja conquista ocorreu a partir da Constituição Brasileira (Brasil, 1988) e na vigência da Lei de Diretrizes e Bases da Educação Nacional (Brasil, 1996), em que os estudantes obtiveram o direito de assumir como opção a inserção em escolas comuns da rede regular de ensino. Assim, com a expansão das matrículas de alunos com deficiência na educação básica, houve também, nas últimas décadas, o aumento da presença desse público nos cursos de nível superior.

No Brasil, de acordo com os dados do Instituto Nacional de Estudos e Pesquisas Educacionais Anísio Teixeira (INEP), houve um aumento das matrículas de pessoas com deficiência no Ensino Superior, alcançando 33.337 em 2014. Dessas, 19.654 $(58,9 \%)$ em instituições privadas e $13.723(41,1 \%)$ em instituições públicas de ensino. Da parcela de estudantes matriculados em instituições públicas, 10.602 (77,3\%) estavam em instituições federais, 2.542 (18,5\%) em estaduais e $579(4,2 \%)$ em municipais (Brasil, 2014).

Esse número tende a se expandir, devido à regulamentação que já vem sendo estabelecido, desde a Constituição Brasileira aos diferentes instrumentos normativos, destacando-se, entre outras a Política Nacional de Educação Especial na Perspectiva da Educação Inclusiva (Brasil, 2008) e, mais recentemente, a Lei Brasileira de Inclusão da Pessoa com Deficiência (Brasil, 2015). Neste contexto, entre as décadas de 1990 e 2000, a educação especial foi formalmente inserida na educação básica e superior, definindo-se seu público alvo (alunos com deficiência, altas habilidades e transtornos globais do desenvolvimento). Toda essa regulamentação permitiu avanços no ingresso desse público, de modo geral no ensino superior, em particular, dos estudantes com deficiência visual (DV).

No cenário atual, os estudantes com deficiência têm garantido, de acordo com as legislações e as ações afirmativas vigentes, o acesso à universidade, no entanto esse alunado enfrenta diversas barreiras no processo de acesso e permanência no ensino superior. Para Almeida, Bellosi e Ferreira (2015), os principais problemas de garantia da permanência desses estudantes nas universidades são justificados pelas especificidades de cada deficiência, pela falta de recursos tecnológicos disponíveis, pelo número reduzido de profissionais especializados e pela ausência de acessibilidade arquitetônica na maioria dos campi.

Em se tratando de alunos com DV, pesquisas acerca da acessibilidade na educação superior indicam barreiras tanto de ordem arquitetônica e comunicacional como na dimensão metodológica e atitudinal. A esse respeito, a pesquisa de Baptistone, Mattos Neto, Toyama e Prais (2017) objetivou compreender as percepções de docentes sobre a inclusão de alunos cegos na educação superior. Os resultados e discussão apontaram que os docentes se sentem despreparados para atender esse alunado indicando serem necessárias várias mudanças desde as suas aulas, materiais didáticos e também na infraestrutura da universidade. Além disso, 70\% apontaram o quão importante seria ao menos uma capacitação para complementar sua formação, pois poderiam se sentir melhor preparados para ministrar aulas no futuro. 
Diante do exposto, esta pesquisa objetivou identificar e analisar as percepções dos estudantes com DV no que tange as dificuldades encontradas quanto à acessibilidade arquitetônica, tecnológica, metodológica e comunicacional do Campus de Belém da UFPA.

\section{Metodologia}

A fim de atingir os objetivos delineados neste estudo, adotou-se a pesquisa caracterizada como exploratório e descritiva quanto ao objetivo (Gil,2008), o estudo de caso quanto ao procedimento (Yin, 2001) e pesquisa quantitativa (Lakatos e Marconi, 2003) e qualitativa (Gil, 2008) quanto á abordagem do problema. O estudo foi operacionalizado por meio da pesquisa de campo e de dados secundários a partir de documentos referentes as leis, decretos e portarias que regem a Educação Especial no sistema educacional brasileiro. A pesquisa visou obter informações sobre as ações de acesso e permanência de estudantes com DV que estudam na UFPA.

\subsection{Ambiente}

A pesquisa foi desenvolvida nas dependências da UFPA Campus do Guamá - Belém. Este campus está dividido em quatro setores: Básico, Profissional, Saúde e Parque de Tecnologia. O campus possui uma população de aproximadamente 20.606 alunos de graduação, disponibiliza 75 cursos de graduação e 70 de pós-graduação¹.

\subsection{Participantes}

O processo de seleção dos participantes foi feito por meio do contato com a Direção Geral do Centro de Registros e Indicadores Acadêmicos (CIAC) e com a Coordenadoria de Acessibilidade (CoAcess) da UFPA sendo solicitado informações referentes aos estudantes com deficiência matriculados na instituição no período de 2012 a 2015. Após apreciação do projeto, estas unidades liberaram uma lista com o nome de 192 estudantes, assim como o curso, o ano de matrícula, o tipo de deficiência, o contato telefônico e o e-mail. Dos 192 estudantes com deficiência que foram contactados, 142 foram excluídos da pesquisa pelos seguintes motivos: um estudante não estudava no Campus do Guamá, 66 alunos afirmaram que a sua deficiência não lhes prejudicava dentro do campus e que conseguiam desenvolver suas atividades acadêmicas sem nenhuma dificuldade, 43 apresentaram problemas com o contato disponibilizado, 22 cancelaram o curso e dez não aceitaram participar do estudo por motivo de força maior, restando 50 estudantes com deficiência. Dentre estes, 50 estudantes com deficiência, 20 apresentavam DV e aceitaram participar deste estudo, sendo nove do sexo feminino (45\%) e 11 do masculino (55\%), 13 se declararam com baixa visão (65\%) e sete com cegueira (35\%). A faixa etária variou entre 18 e 38 anos de idade.

\subsection{Instrumentos de Recolha de Dados}

Para recolha dos dados, um questionário sociodemográfico e acadêmico foi adaptado e aplicado. Este instrumento foi dividido em duas etapas sendo a primeira constituída por perguntas fechadas referentes ao levantamento de variáveis sociodemográficas e acadêmicas nos seguintes tópicos: (1) identificação, (2) caracterização da deficiência, (3) trajetória escolar, (4) vestibular/Exame Nacional do Ensino Médio (Enem), (5) atividades acadêmicas, (6) grupo familiar, situação socioeconômica, (7) alimentação e (8) transporte. A segunda parte desse instrumento foi elaborado a partir de um roteiro de entrevista semiestruturado composto por 40 perguntas abertas divididas em cinco dimensões que versaram sobre acessibilidade em geral que segundo Sassaki (2011) são constituídas por seis dimensões. Para este estudo, utilizou-se quatro dimensões: (1) arquitetônica, relacionada à eliminação de barreiras ambientais físicas nos espaços urbanos, nos edifícios e no transporte coletivo; (2)

${ }^{1}$ UFPA 2018 EM NÚMEROS: ANO BASE 2017. Recuperado de: http://www.ufpanumeros.ufpa.br/index.php/3-ensino 
comunicacional, que trata de possibilitar a comunicação nos seus diversos suportes; (3) metodológica que aborda a flexibilização dos métodos e técnicas de estudo, trabalho e produção; e (4) instrumental, que visa a flexibilização no uso de instrumentos e ferramentas de estudo, trabalho e lazer. Este instrumento possibilitou obter informações específicas relativas aos serviços oferecidos pela instituição, onde os participantes puderam responder se o apoio existia ou não, se era adequado ou não, se aplicável a instituição ou não, ou se o estudante conhecia ou desconhecia o serviço.

A coleta de dados ocorreu nas dependências físicas da universidade, em horário pré-estabelecido pelos participantes e que não interferiu nas atividades acadêmicas dos mesmos. No início da entrevista, cada participante foi informado dos objetivos gerais do estudo, formalizado o convite para participação e assinado o Termo de Consentimento Livre Esclarecido, garantindo a participação voluntária, a confidencialidade e o anonimato.

\subsection{Análise dos Dados}

As informações obtidas neste estudo permitiram tanto um tratamento quantitativo descritivo como um tratamento qualitativo onde os discursos dos entrevistados foram analisados utilizando a proposta de Análise de Conteúdo de Bardin (2006). Os depoimentos foram agrupados nas seguintes dimensões de análise: (a) acessibilidade arquitetônica em geral, (b) acessibilidade arquitetônica, (c) acessibilidade tecnológica, (d) acessibilidade metodológica, e (e) acessibilidade comunicacional.

\section{Resultados e Discussão}

\subsection{A percepção sobre a acessibilidade arquitetônica em geral da UFPA}

A Tabela 1, apresenta os dados que foram agrupadas em duas categorias: percepção positiva e percepção negativa. No que se refere à acessibilidade em geral, 48,7\% estavam satisfeitos e 51,3\% demonstraram insatisfação neste item. Já no que se refere à acessibilidade arquitetônica no campus, 56,1\% apresentaram respostas positivas ao apoio oferecido pela instituição, por outro lado, 43,9\% demonstraram percepção negativa em relação a essa dimensão. Quanto à acessibilidade tecnológica, 50,6\% acharam que esses recursos estavam a contento e $49,9 \%$ se manifestaram negativamente em relação a esses serviços. No que diz respeito à acessibilidade metodológica, 39,2\% responderam estarem satisfeitos com suas atividades acadêmicas e 60,8\% relataram que não estavam felizes com as adequações disponibilizadas pela instituição. Por fim, quanto à acessibilidade comunicacional, observou-se que 30,7\% dos entrevistados se disseram satisfeitos apresentando percepção positiva neste aspecto, enquanto que $69,3 \%$ reclamaram dos serviços.

Tabela 1 - Percepção acerca da Acessibilidade na UFPA.

\begin{tabular}{lll}
\multirow{2}{*}{ Categorias } & \multicolumn{2}{l}{ Avaliação } \\
\cline { 2 - 3 } & Percepção positiva & Percepção negativa \\
\hline Acessibilidade total geral & $48,7 \%$ & $51,3 \%$ \\
Acessibilidade arquitetônica & $56,1 \%$ & $43,9 \%$ \\
Acessibilidade tecnológica & $50,6 \%$ & $49,9 \%$ \\
Acessibilidade metodológica & $39,2 \%$ & $60,8 \%$ \\
Acessibilidade comunicacional & $30,7 \%$ & $69,3 \%$
\end{tabular}

Fonte: Autores.

Os dados recolhidos permitiram tecer algumas reflexões em torno do acesso e permanência desse público na instituição. No que se refere aos serviços de acessibilidade em geral, verificou-se que os estudantes com DV (48,7\%) revelaram reconhecer 
os esforços que vêm sendo feitos pela UFPA para melhorar as condições oferecidas e da importância desses serviços em sua trajetória acadêmica, o que vai ao encontro de outros estudos que tratam do mesmo tema (Duarte et al. 2013; Bisinoto \& MarinhoAraújo, 2014).

No entanto, o presente estudo mostra que a acessibilidade em geral na UFPA não atende às necessidades dos estudantes com DV, pois mais da metade dos participantes $(51,3 \%)$ relatou insatisfação com os serviços oferecidos pela instituição. Neste sentido, Duarte et al. (2013) argumentam que para se alcançar uma educação inclusiva de qualidade, os gestores precisam investir na produção e distribuição de materiais pedagógicos apropriados, na qualificação dos docentes, assim como na infraestrutura adequada para ingresso, isto é, na acessibilidade em geral. O conceito de acessibilidade, segundo Massmann (2014), que inicialmente se referia a criar condições de mobilidade no espaço urbano foi recebendo contribuições de outras áreas referentes à comunicação, conforto, segurança e autonomia das pessoas em geral, não somente das pessoas com deficiência.

\subsection{A percepção sobre a acessibilidade arquitetônica na UFPA}

Os estudantes reportaram uma avaliação positiva (56,1\%), mas com algumas restrições quanto ao se locomover sem ajuda de terceiros com rotas acessíveis, dos pisos adequados e estáveis e da altura da localização dos obstáculos aéreos no campus:

Utilizo com independência as entradas principais da instituição, não tendo que receber auxílio para o interior da universidade por meio de ajuda de terceiros. A proteção de obstáculos aéreos não é oferecida, alguns acabam se batendo, por galhos, então não é 100\% (Baixa Visão).

Em boa parte, sim existe piso tátil, mas os que têm, estão com defeito, cheio de problemas (Cegueira).

Em relação aos pontos negativos (43,9\%), os estudantes destacaram as dificuldades relacionadas à locomoção e as rotas inacessíveis, aos pisos instáveis e quebrados, a altura equivocada dos obstáculos, poucos ônibus circulares, da precária iluminação à noite e da insegurança dentro do campus:

Não utilizo com independência as entradas principais da UFPA, porque eu sempre preciso que alguém me atravesse por causa dos portões. Eu tenho medo de atravessar e algum carro vim (Baixa Visão).

Tem uma escuridão imensa no caminho, e até chegar naquele caminho do Restaurante Universitário, eu já cai, já tropecei, por conta da própria iluminação, que é fraca. Nos ônibus, falta acessibilidade, e eles faltam rodar mais, porque são só dois e demora muito a passar (Baixa Visão).

Nesta dimensão, percebeu-se que 56,1\% dos participantes relataram benefícios em relação a acessibilidade na UFPA. Mencionaram que a retirada das barreiras arquitetônicas tem sido relatada como uma das principais conquistas em termos de acessibilidade às pessoas com deficiência, até por conta da sua visibilidade. No entanto, os participantes ainda enfrentam desafios para chegar ao campus, ir de um local a outro e, ainda, sair e entrar na universidade em condições adequadas e seguras. Para Fischer (2014), esses desafios geram riscos à integridade física pois, essas dificuldades relacionadas à acessibilidade geram nos estudantes constrangimentos que alimentam sentimentos relacionados à exclusão. Esta indiferença passa a ser percebida pelo estudante como negativa, e impeditiva do exercício autônomo e de inserção nas práticas cotidianas, comprometendo suas atividades acadêmicas.

Neste sentido, dentre os vários decretos e leis que vem sendo implementados pelo Governo Brasileiro desde a década de 1990, pode-se mencionar um programa que foi criado para efetivar o acesso e permanência do estudante com deficiência no 
Ensino Superior: o Programa Acessibilidade na Educação Superior - Incluir que objetivou criar e estruturar os núcleos de acessibilidade nas universidades federais com o intuito de garantir o acesso de estudantes, docentes e servidores com deficiência em todos os espaços, ações e processos, buscando seu pleno desenvolvimento acadêmico (Brasil, 2013).

\subsection{A percepção sobre a acessibilidade tecnológica na universidade}

Observou-se que os participantes fizeram uma avaliação positiva (50,6\%) em relação à acessibilidade tecnológica, mas também com algumas advertências quanto à atuação da inclusão quando mencionaram o atendimento em relação ao uso dos computadores e de sintetizadores de voz ou ampliações de tela:

Na verdade, todos os computadores da universidade são razoáveis, mas deveriam ter mais acessibilidade porque se der pane naquele lá que eu uso já éra pra mim, porque nenhum outro tem. E as outras pessoas que vão usar deviam ter a responsabilidade de saber mexer e não avacalhar tudo (Cegueira).

O Jaws dá uma maior independência pra gente, o Dosvox ele é muito limitado em relação à gente fazer trabalho, ele lê aquilo o que vocês tão vendo no menu. A questão é que no Sul, nos outros Estados brasileiros eles não usam mais o Dosvox, é só o Jaws, então o que falta na universidade é ter um curso pra ensinar os deficientes também a utilizar o Jaws (Cegueira).

Ela só oferece o Dosvox que é muito bom, só que ele não é o completo, se tivesse o Jaws, NVDA e o Dosvox seria completo, porque o que um programa não tem o outro tem, os três se completam. Então um completa o outro, e o setor só tem o Dosvox, e o computador é velho (Cegueira).

Quanto às limitações apontadas pelos estudantes, 49,9\% destacaram dificuldades relacionadas ao tempo insuficiente para digitalização dos textos disponibilizados no setor Braille da Biblioteca Central da UFPA e dos problemas de manutenção e conservação dos computadores nos diversos locais da instituição:

Se tu fores ao setor Braille não é adequado, mas se tu pagares é adequado. Demora, eles não dão conta da demanda, porque é só um estagiário de manhã e outro a tarde, e uma senhora que toma conta (Baixa Visão).

A universidade como um todo não possui texto digitalizado. O espaço Braille é o único local em que nós temos acesso ao texto já digitalizado é de alunos que já passaram por aqui, mas se eu for lá na minha faculdade eu já não encontro. Se eu for no espaço, na biblioteca central eu não encontro lá onde todo mundo usa, só aqui no espaço Braille da biblioteca (Cegueira).

Os computadores não são adequados e são antigos e se eu tivesse baixa visão dos dois lados, eu não conseguiria digitar nada, porque ele não tem o liso o teclado, não tem brailezinho, não tem comando de voz (Cegueira).

A UFPA deveria ter um site oficial, acessibilidade na Web. Deveria ter naqueles espaços, espaço para inclusão, informando o que a UFPA oferece, acho que deveria ter isso, um site (Baixa Visão).

Observou-se que apesar dos 50,6\% dos participantes manifestaram satisfação com os serviços oferecidos, notou-se um descontentamento com relação aos computadores e com os serviços oferecidos pelo setor Braille da Biblioteca Central da UFPA. Pode-se observar que o estudante demonstra ter conhecimentos dos recursos de acessibilidade ao computador, como por exemplo, os programas ledores de telas, o Jaws, Dosvox, NVDA, o uso do comando de voz e da linha Braille, como as 
impressoras Braille e os ampliadores de tela, no entanto apesar desses recursos serem disponibilizados aos alunos como forma de garantir o acesso a esse sistema operacional, ainda assim, está muito deficitário.

Neste sentido, os alunos com DV contam com o apoio da Portaria $n^{\circ}$. 3.284 (Brasil, 2003) que exige alguns requisitos de acessibilidade nas bibliotecas do Ensino Superior, tomando-se como referência a NBR 9050 da Associação Brasileira de Normas Técnicas (ABNT, 2004). Com relação a esse público, o compromisso da instituição se estende do início à conclusão do curso superior tendo como compromisso disponibilizar os seguintes itens: a) manter sala de apoio equipada com máquina de datilografia Braille, impressora Braille acoplada ao computador, sistema de síntese de voz, gravador e fotocopiadora que ampliem textos, software de ampliação de tela, equipamento para ampliação de textos para atendimento ao estudante com visão subnormal, lupas, réguas de leitura, scanner acoplado a um computador; e b) adotar um plano de aquisição gradual de acervo bibliográfico em Braille e de fitas sonoras para uso didático (Brasil, 2003). A Lei 13.146 destaca que a tecnologia assistiva refere-se a distintos produtos, recursos, ou metodologias e práticas que promovam a funcionalidade, relacionada à atividade e à participação da pessoa com deficiência ou com mobilidade reduzida, visando assim à sua autonomia, independência, qualidade de vida e inclusão social (Brasil, 2015).

Notou-se uma desinformação no que se refere a acessibilidade digital no site da UFPA. As universidades federais públicas têm disponibilizado as suas informações na Internet, mas ainda há muito o que fazer para que as informações disponíveis aos alunos com deficiência possam ser acessadas pelos mesmos. A UFPA segue as diretrizes do e-MAG (Modelo de Acessibilidade em Governo Eletrônico), conforme as normas de Governo Federal, em obediência ao Decreto 5.296 (Brasil, 2004). O e-MAG está alinhado as recomendações internacionais, mas estabelece padrões de comportamento acessível para sites governamentais. O e-MAG fornece informações as pessoas com deficiência para que consigam acessar a web em melhores condições fornecendo informações e serviços, no mundo físico, já que não podem ler material impresso ou locomover-se até determinado local, entre outras barreiras de acessibilidade.

\subsection{A percepção sobre a acessibilidade metodológica na UFPA}

Verificou-se que os alunos fizeram uma avaliação satisfatória (39,2\%) em relação à acessibilidade metodológica que diz respeito ao tempo para realizar as provas, a utilização de slides e de outros recursos audiovisuais, o aumento da fonte dos textos, imagens, na elaboração do material escrito e de como o professor verbalizava com clareza os conteúdos que ministra em sala de aula:

Alguns dão tempo para fazer as provas sim, outros não. Eles tentam utilizar slides e outros recursos audiovisuais e costumam aumentar a fonte dos textos, imagens (Baixa Visão).

A professora desse semestre foi muito acessível, explicava tudo o que ela fazia bem detalhadamente, e aí quando ela terminava de explicar, ela vinha e explicava de novo pra mim. (Cegueira).

A maioria verbaliza com clareza sua aula. Isso é uma coisa muito pessoal, porque tem aquelas pessoas que tem o dom, mas existem aquelas que têm o conhecimento, mas não sabem transmitir (Baixa Visão).

Uma capacitação dos professores para eles lidarem melhor com esses alunos, porque às vezes eles tentam, mas não conseguem, então tem que ter uma sensibilização desses professores (Cegueira).

Ainda nesse domínio, observou-se que os alunos fizeram uma avaliação negativa $(60,8 \%)$, quanto à falta de tempo para realizar as provas, a ausência na utilização de slides e de outros recursos audiovisuais, na inexistência do aumento da fonte dos 
textos e de imagens, o não preparo na elaboração do material escrito e da falta de didática ao verbalizar com clareza os conteúdos ministrados em aula:

Os professores eu acho que desconhecem, ou então, porque se não, teria uma preocupação melhor, né, com o material didático, com os slides propriamente dito, com as provas, perguntar se eu estou enxergando ou não, se eu estou com uma dificuldade ou não. Pelo contrário ele até reduz o tempo da prova, como chegar sem a prova ampliada, ele coloca alguém pra vigiar, distribui a prova e vai ampliar a minha, quando ele volta de lá eu já perdi 25, 30 minutos e o prazo é o mesmo (Baixa Visão).

Os professores quando chegam em sala de aula e se deparam com um aluno cego, eles ficam sem saber como agir, não sabem. Alguns declaram isso logo, outros ficam escondendo e tentando arrumar alguma forma de expor o que está no slide. Na maior parte são próprios colegas de sala que fazem a leitura dos slides (Cegueira).

Não existe nenhuma adaptação para leitura aqui na Faculdade, tudo o que eu consigo eu vou por fora, falo direto com o professor. Mas a faculdade mesmo não está preparada para receber uma pessoa com deficiência, principalmente baixa visão (Baixa Visão).

"Professor, olha, eu preciso de slide com fundo preto e letra branca", ele chega lá com o fundo todo colorido, cheio de imagem, letra pequenininha, mas tem uns que tentam mas não sabem como fazer (Baixa Visão).

No que se refere a acessibilidade metodológica, $60,8 \%$ dos participantes relataram suas experiências negativas acerca dessa dimensão na UFPA. Apontaram a desatenção e a falta de bom-senso dos docentes que prejudicam o processo de ensino e aprendizagem do aluno por condutas negligentes. Os alunos reclamaram de avaliações que não melhora em nada a situação pedagógica estabelecida e de uma postura indiferente às necessidades individuais do aluno (Benevides, 2011). Os depoimentos sobre a relação entre professor e aluno confirmaram que as adaptações realizadas nas metodologias de ensino e de avaliação dependem da disponibilidade pessoal ou da boa vontade do docente de fazer as adaptações ou não.

Para Rocha (2017), ensinar pessoas com DV, só será possível se os professores compreenderem como se dá a aquisição de conhecimento por esses estudantes e quais fatores influenciam no aprendizado. Esta relação pode levar estudantes e professores a ampliarem relações concretas de interação que contribuam para o processo de aprendizagem dos mesmos. É de fundamental importância que o docente invista em conteúdos bem definidos, métodos e técnicas adequadas e material didático apropriado.

Percebeu-se que apesar das indefinições metodológicas, os professores procuram estabelecer uma relação de proximidade com os alunos, de modo a suprir da melhor maneira possível as necessidades educacionais desse alunado. Acreditase que a concepção de ensino não pode estar limitada a uma única forma de ensino, mas que a ação e intervenção pedagógicas devem ser diversificadas e ajustadas às particularidades de cada um, independentemente se é aluno com deficiência ou não, levando-se em consideração o bom senso do docente. A acessibilidade metodológica destacada pelos participantes não oferece as condições necessárias para o desenvolvimento do aluno com DV. As práticas docentes relatadas acabam por reproduzir a exclusão presente nos cursos de graduação da UFPA, não possibilitando ao mesmo, uma participação ativa e democrática em sua vida acadêmica. 


\subsection{A percepção sobre a acessibilidade comunicacional na universidade}

Quanto à acessibilidade comunicacional, verificou-se que os alunos fizeram uma avaliação positiva $(30,7 \%)$ com algumas limitações, quanto ao material de divulgação em Braille e em relação ao conhecimento de Braille por parte dos funcionários e docentes:

Eles fazem um panfleto, fazem uma divulgação e colocam uma letra ainda menor do que você já consegue ver, aí fica bem pequenininho, mais do que já dá o normal. (Baixa Visão).

Os funcionários que estão na UFPA... não tem o número de funcionários necessários para atender a demanda, é um número bem reduzido. Eu, pelo menos, nunca fui auxiliado, nesse sentido (Cegueira).

Ainda quanto a essa dimensão, verificou-se que os alunos fizeram uma avaliação negativa (69,3\%), quanto ao material de divulgação em Braille, a incapacidade dos funcionários e professores de ler Braille, a inexistência de um contato entre a faculdade (direção), os professores, os alunos com deficiência, entre o setor Braille e o CoAcess com a confecção do material (programação, inscrição e pagamento) em Braille nos eventos promovidos pela instituição, com a falta de informação acerca dos auxílios para pessoas com deficiência (PCD) e com a inacessibilidade na Web, como observado nos relatos:

Tipo panfletos anunciando cursos..., em Braille, não tem (Baixa Visão).

Os funcionários e professores deveriam ter essa qualificação dentro dos cursos de graduação, porque agora que tem pra Libras, que antes não tinha. Existe uma lei que diz que o professor da universidade tem que ter essa qualificação dentro da sua graduação, e isso na prática não acontece (Cegueira).

O professor manda a prova por e-mail para faculdade, a faculdade envia pro setor Braille, aí o setor Braille manda do e-mail do setor Braille pra faculdade, porque é documento oficial, que manda pra esse professor que eu tive essa treta, ele já passava a levar a minha prova ele mesmo lá, porque depois ele perdeu uma prova minha, enfim muita confusão (Cegueira).

Na minha faculdade não tem, como um todo para universidade que foca para todos os cursos, que é o CoAcess. mas na minha faculdade não existe uma coordenação como essa. Eu falo que não porque inclusive para eu conseguir um livro o professor deu o que tinha no computador dele (Cegueira).

Eu acho que os núcleos e as faculdades deveriam ser mais unidos, para que eles pudessem executar um trabalho que assessorasse a gente de uma maneira mais direta. Essa bolsa para deficiência eu não sabia que tinha, eu sei que tem o auxílio moradia. Eu sei desses auxílios, mas o específico pra pessoa com deficiência eu não sabia que tinha (Cegueira).

No que se refere a acessibilidade comunicacional, 69,3\% dos participantes relataram suas experiências negativas acerca dessa dimensão na UFPA. Esses obstáculos se apresentaram quando não se dispõem de recursos materiais como livros apropriados ao tipo de DV e tecnologias assistivas. Entende-se que para possibilitar ao aluno com DV à acessibilidade comunicacional é necessário eliminar as barreiras tanto na comunicação interpessoal, como na comunicação escrita e/ou digital. Para tanto, é importante que a UFPA ofereça serviços, como textos em Braille, textos com letras ampliadas para quem tem baixa visão, notebook e outras tecnologias assistivas.

Neste sentido, o Espaço Braille da UFPA promove esta comunicação, pois possui computadores equipados com os sistemas Dosvox, NVDA (leitores de tela) e Super Nova (software para ampliar até 64 vezes o conteúdo da tela), além de 
impressora Braille, lupas manuais e eletrônicas, dentre outras ferramentas que promovem a acessibilidade aos usuários. O scanner acoplado ao computador é utilizado para a digitalização de textos que posteriormente podem ser ouvidos pelos alunos por meio do computador com sintetizador de voz ou impressos em Braille. Esse serviço de digitalização é um recurso muito utilizado e requisitado pelos alunos com DV. No entanto, observou-se a falta de material digitalizado e processado em Braille em tempo hábil, pois o corpo docente não se organiza com a antecedência necessária para que sejam realizadas e o espaço ainda precisa de mais mão de obra qualificada para dar conta da demanda dos pedidos de digitalização. Essa barreira se mostra responsável por uma série de entraves ao aprendizado do aluno com DV.

Acredita-se que a comunicação entre o Espaço Braille e o professor ainda está muito lenta e que carece ser imediata, pois os professores precisam saber com muita antecedência quem são seus estudantes com deficiência. Neste sentido, observase que a UFPA disponibiliza o CoAcess que tem por objetivo de promover o acesso e a permanência aos estudantes com deficiência, Transtorno do Espectro Autista e Altas Habilidade/Superdotação que estudam na instituição, desde 2009 impulsionando políticas de inclusão por meio de ações que promovam acessibilidade.

As coordenações e/ou núcleos de acessibilidade foram criadas nas universidades públicas federais com o objetivo, de acordo com o Decreto n 7.611, de eliminar barreiras físicas, de comunicação e de informação que restringem a participação e o desenvolvimento acadêmico e social de estudantes com deficiência (Brasil, 2011). O CoAcess tem por objetivo prover ações voltadas a orientações para docentes, discentes, técnicos-administrativos e gestores de forma a adequar o fazer pedagógico para que possam acessar os conteúdos curriculares em condições de igualdade. Neste sentido, defende-se a ideia de que exista uma participação maior entre esses três setores para que o aluno com deficiência possa se sentir acolhido e assistido pela sua faculdade e pelas coordenações e/ou núcleos de acessibilidade.

Assim, acessibilidade comunicacional destacada pelos estudantes ainda não oferece as condições necessárias para o desenvolvimento do aluno com DV. Observou-se nos relatos a falta de sensibilidade dos professores e de outros setores da instituição no que se refere a uma comunicação mais visível e solidária. Chahini (2010) destaca que os docentes do Ensino Superior não estão preparados para atender as necessidades educacionais dos estudantes com deficiência. Seus relatos indicam a necessidade de serem revistas as metodologias utilizadas, a reorganização do tempo, do plano de aula e da adaptação dos materiais didáticos de acordo com as especificidades de cada estudante.

Verificou-se também a desinformação dos participantes em relação aos auxílios financeiros que a UFPA oferece aos estudantes com DV. A instituição necessita investir mais nos meios de comunicação para que esse público saiba dos seus direitos e, assim, requerer os auxílios PCD e o Kit PCD. Por meio desses recursos, eles podem custear transporte, alimentação, material didático e materiais de alto custo, a exemplo de computadores com programas de tecnologias assistivas.

\section{Considerações Finais}

O presente estudo objetivou descrever e analisar as percepções dos estudantes com DV no que tange as dificuldades encontradas quanto à acessibilidade arquitetônica, tecnológica, metodológica e comunicacional do Campus de Belém da UFPA. Os participantes fizeram uma avaliação negativa da instituição em relação as barreiras de acessibilidade existentes e, para esses estudantes, alguns desses obstáculos precisam ser reavaliados, que por sua vez, necessita se estruturar para atender as necessidades educacionais específicas desse alunado e oferecer os recursos necessários para favorecer o acesso e permanência desse público na universidade.

O dado mostra que não há suporte, na universidade, em relação aos recursos didáticos que possibilitem acessibilidade do aluno com DV ao processo de ensino e aprendizagem. Verificou-se a ausência de uma formação adequada, que subsidie a prática pedagógica do docente, que possa, com efeito, auxiliar os alunos em sua aprendizagem. Observou-se uma lacuna existente, no que diz respeito ao material didático pedagógico inclusivo, relativo a conteúdos necessários aos processos de ensino 
e aprendizagem. O professor, assim como a faculdade precisam saber com muita antecedência que terá um aluno com deficiência em suas dependências e se organizar para recebê-lo com responsabilidade e atenção.

Identificou-se que é necessária uma comunicação mais eficaz entre o estudante com DV com o CoAcess, as faculdades e o setor Braille. Esse dado aponta que a instituição precisa reavaliar tal comunicação, uma vez que a parceria entre esses três setores poderá contribuir para a eliminação das barreiras comunicacionais.

A partir dos dados encontrados, observou-se que a inclusão escolar de estudantes com DV no Ensino Superior mostrase desafiadora, pois ainda são muitas as barreiras encontradas e ainda há muito que precisa ser efetivado. Desse modo, acreditase que a análise da percepção dos entrevistados acerca de sua própria inclusão pode contribuir para a manutenção acadêmica do mesmo na instituição, assim como para guiar os gestores da UFPA na implementação de medidas que promovam o acesso e permanência na instituição.

Apesar de restrito a uma única instituição e com um número reduzido de participantes, sugere-se a continuidade de estudos relativos a essa temática, com a inclusão de mais participantes e de outras instituições de Ensino Superior para melhor conhecer a realidade desse alunado.

\section{Referências}

Almeida, J. G. A., Bellosi, T. C., \& Ferreira, E. L. (2015). Evolução da matrícula de pessoas com deficiência na educação superior brasileira: subsídios normativos e ações institucionais para acesso e permanência. Revista Iberoamericana de Estudos em Educação, 10 (esp), 643-660.

Associação Brasileira de Normas Técnicas - ABNT (2004). NBR 9050: 1994. Acessibilidade de pessoas portadoras de deficiências a edificações, espaço, mobiliário e equipamento urbanos. ABNT.

Baptistone, G. F., Mattos Neto, I. A., Toyama, K. S. F. \& Prais, J. L. de S. (2017). A inclusão do aluno cego na educação superior: percepções de professores de um curso de licenciatura em Química. ACTIO, 2(1), 98-121. 10.3895/actio.v2n1.6718

Bardin, L. (2006). Análise de Conteúdo. Edições 70.

Benevides, M. C. (2011). Avaliação da aprendizagem de alunos com deficiência: estudo de caso em uma instituição de ensino superior da rede pública de Fortaleza-Ceará. Dissertação de Mestrado, Universidade Federal do Ceará, Fortaleza, CE, Brasil.

Bisinoto, C., \& Marinho-Araújo, C. M. (2014). Sucesso acadêmico na Educação Superior: contribuições da Psicologia Escolar. Revista E-Psi, 4(1), 28-46.

Brasil (2013). Programa incluir, acessibilidade na educação superior - Documento orientador. SECADI/SESu.

Chahini, T. H. C. (2010). Atitudes Sociais e Opiniões de Professores e Alunos a Universidade Federal do Maranhão em relação à Inclusão de Alunos com Deficiência na Educação Superior. Tese de Doutorado, Universidade Federal do Maranhão, São Luís, MA, Brasil.

Decreto $n^{\circ} 5.296$ de 2 de dezembro de 2004 (2004, 2 de dezembro). Regulamenta as Leis n. 10.048/2000, que dá prioridade de atendimento às pessoas que especifica, e n. 10.098/2000, que estabelece normas gerais e critérios básicos para a promoção da acessibilidade das pessoas portadoras de deficiência ou com mobilidade reduzida, e dá outras providências. http://www.planalto.gov.br/ccivil_03/_Ato2004-2006/2004/Decreto/D5296.htm

Decreto $n^{\circ} 7.611$, de 17 de novembro de 2011 (2011, 17 de novembro). Dispõe sobre a educação especial, o atendimento educacional especializado e dá outras providências. Brasília, DF. http://www.planalto.gov.br/ccivil_03/_Ato2011-014/2011/Decreto/D7611.htm

Duarte, E. R., Rafael, C. B. S., Filgueiras, J. F., Neves, C. M., \& Ferreira, M. E. C. (2013). Estudo de caso sobre a inclusão de alunos com deficiência no Ensino Superior. Revista Brasileira de Educação Especial,19(2), 289-300.

Fischer, J. (2014). Inclusão de acadêmicos com deficiência na universidade: Possibilidades e desafios. In: Orrú, S. E. (Org.). Para além da educação especial: avanços e desafios de uma educação inclusiva (pp. 87-102). Wak editora.

Gil, A. C. (2008). Métodos e Técnicas de pesquisa social. (6a ed.), Editora Atlas.

Instituto Nacional de Estudos e Pesquisas Educacionais Anísio Teixeira [Inep] (2014). Sinopses estatísticas da Educação Superior - graduação: censo da Educação Superior de 2014. http://portal.inep.gov.br/superior-censosuperior-sinopse

Lei n. 9.394, de 20 de dezembro de 1996 (1996, 20 de dezembro). Estabelece as diretrizes e bases da educação nacional. Brasília, DF: Diário Oficial [da] República Federativa do Brasil., p.27.833.

Lei $n^{o}$ 13.146, de 6 de julho de 2015 (2015). Institui a Lei Brasileira de Inclusão da Pessoa com Deficiência (Estatuto da Pessoa com Deficiência). http://www.planalto.gov.br/ccivil_03/_Ato2015-2018/2015/Lei/L13146.htm.

Lakatos, E, M., \& Marconi, M. de A. (2003). Fundamentos de Metodologia Científica. (5a ed.), Atlas. 
Research, Society and Development, v. 10, n. 4, e26110414076, 2021

(CC BY 4.0) | ISSN 2525-3409 | DOI: http://dx.doi.org/10.33448/rsd-v10i4.14076

Portaria $n^{\circ} 3.824$ de 07 de novembro de 2003 (2003, 07 de novembro). Dispõe sobre requisitos de acessibilidade de pessoas portadoras de deficiências, para instruir os processos de autorização e de reconhecimento de cursos, e de credenciamento de instituições. Brasília, DF: Diário Oficial [da] República Federativa do Brasil, nº 219, Seção 1, p. 1.

Rocha, A. B. O. (2017). O papel do professor na educação inclusiva. Ensaios Pedagógicos, 7(2). http://www.opet.com.br/faculdade/revistapedagogia/pdf/n14/n14-artigo-1-O-PAPEL-DO-PROFESSOR-NA-EDUCACAO-INCLUSIVA.pdf

Massmann, D. (2014). Acessibilidade: sentidos em movimento. In: Ferreira, E. L. \& Orlandi, E. P. (Orgs.). Discursos sobre a inclusão (pp. 191-224). Intertexto.

Sassaki, R. K. (2011) Acessibilidade na inclusão escolar e laboral. In: Ferreira, E. L. (Org.), Atividades físicas inclusivas para pessoas com deficiência (pp. 197227). Niterói: Intertexto.

Yin, R. K. (2001). Estudo de Caso: Planejamento e Métodos. (2a ed.), Bookman. 